\title{
Jigsaw teaching method for collaboration on cloud platforms
}

Keywords: jigsaw method; collaborative learning; social connectedness; cultural difference; Google Classroom

\section{Introduction}

Collaborative learning is a popular teaching style defined as 'instructional arrangements that involve two or more students working together on a shared learning goal' (Asterhan \& Schwarz, 2016; Gillies \& Boyle, 2008). Some benefits of collaborative learning for instructors include positive interaction and active participation among students, e.g. asking questions, elaborating opinions, exchanging ideas, improving knowledge, and strengthening motivation. (Slavin, 2014) as it was shown to outperform independent work (Gillies, 2003). The effectiveness of collaborative learning is based on the structure of groups, which can be set by teachers, by students, or randomly assigned (Chen \& Kuo, 2019). However, learning outcomes of groups may differ owing to factors such as individual personal characteristics, cultural backgrounds, and prior knowledge (Zambrano, Kirschner, Sweller, \& Kirschner, 2019). Active collaborative learning also mediates the relationship between interactivity and learning performance (Chan, Wan, \& Ko, 2019). Collaborative learning in small groups is influenced by converge or divergence of knowledge (Weinberger, Stegmann, \& Fischer, 2007).

An important innovation in collaborative learning research is the relatively recent field of computer-supported collaborative learning (CSCL) (Stahl, 2013), which enhanced effective knowledge construction process (Weinberger \& Fischer, 2006; Noroozi, Weinberger, Biemans, Mulder, \& Chizari, 2013), quality of interaction and learning outcomes of group-based learning (Strijbos, Martens, \& Jochems, 2004). Applications such as cloud-based environments, MOOCs, and IRS can effectively support collaborative learning for students; Google applications (e.g. G suite for Education, Google Drive, Docs, Slides, and Sheets) are particularly useful. Studies on the use of Google applications have indicated that students prefer discussion and collaboration, have positive attitudes towards collaborative platforms, and interact effectively in group projects and that these platforms positively influence intention (Bennett \& Pence, 2011; Deton, 2012; Huang, 2017). Studies showed that the application of technology (Al-Samarraie \& Saeed, 2018) and the jigsaw method (van 
Leeuwen \& Janssen, 2019) can improve teaching and learning. Combining the jigsaw method with case discussions is more effective than case discussions alone (Pozzi, 2010). Hence, literature indicated the gap in understanding the effects of jigsaw method integration using cloud-based environments.

Further, collaborative learning performance may be affected by cultural differences (Hofstede, 1986). Spires, Paul, Himes, and Yuan (2018) indicated that cross-cultural collaborative disciplinary inquiry enhances the demonstration and development of students' abilities. Effective classroom management in terms of cultural responsiveness needs to be strategically incorporated to avoid negative behaviour, which is often present in cases of inadequate classroom management (Gaias, Johnson, Bottiani, Debnam, \& Bradshaw, 2019). The dialogic approach (Alghasab, Hardman, \& Handley, 2019), teacher' guidance (van Leeuwen \& Janssen, 2019) paired with the exposure to different cultural backgrounds (Popov et al., 2014; Denessen, Driessen, Smit, \& Sleegers, 2001; Bear et al., 2016) have been shown to enhance the collaborative process (Spires, Paul, Himes, \& Yuan, 2018; Chan, Wan, \& Ko, 2019).

Han, Eom, and Shin (2013) indicated that multimedia teaching and the use of Internet-based teaching methods break the constraints of limited resources. Computerassisted teaching is considerably more effective than traditional methods (Benson, 2008; Gürbüz \& Birgin, 2012). By integrating technology and the jigsaw method, participation, discussion, and knowledge-sharing can be improved. The jigsaw-based teaching applies to case discussion. Students with different cultural backgrounds could exchange thoughts on the collaborative cloud platform. Google Classroom allows users to post, upload, and interact during collaboration and Google Slides enables students to collaboratively work from different devices simultaneously. Hence, this research will employ a jigsaw-based case discussion to Google Classroom (with Google Slides) to (1) enhance the effectiveness of within-group cooperation and (2) enhance the efficiency of cross-group collaboration.

\section{Literature Review}

\section{Jigsaw Method and Cultural Differences}

Collaborative learning techniques have been promoted for school desegregation and abuse prevention (Moskowitz, Malvin, Schaeffer, \& Schaps, 1985). Collaborative learning methods can improve students' attitudes towards peers and academic performance. Jigsaw is a cooperative learning technique that allows students to teach 
part of the curriculum to peers (in small groups) and cultivates student interdependence through the learning tasks. Buhr, White, and Pinheiro (2014) reported that jigsaw is an effective teaching method for use with medical students. The jigsaw teaching strategy can be used for theoretical education to improve self-regulated learning and academic motivation (Sanaie, Vasli, Sedighi, \& Sadeghi, 2019). Charlier, Stocl, and Iserbyt (2015) investigated the quality of peer-assisted learning in the jigsaw method and revealed that it was as effective as expert instruction. Students favoured the jigsaw method for its ability to improve problem-solving skills, communication skills, and cooperative learning more than traditional didactic lectures (Wilson, Pegram, Battise, \& Robison, 2017; Benson \& Anderson, 2010). In addition to promoting group cooperation, jigsaw-based collaborative learning can enhance the quality and performance of teamwork, but it is mainly valued by students older than 22 years (Leyva-Moral \& Camps, 2016). Pozzi (2010) used case discussions with the jigsaw method and indicated that collaborative activities with different structural levels can foster discussion and enhance collaboration.

Cultural background (Hofstede, 1986) has been shown to be a critical dimension of collaborative learning; language barriers, in particular, may pose challenges to students. Zhou and Li (2015) indicated that cultural differences in classroom management had a significant effect and these differences may result in a cultural mismatch. Popov et al. (2014) discovered that students with individualist cultural backgrounds exhibited negative perceptions of collaborative learning. Collective case study also fosters the demonstration and development of students' educational capabilities in cross-cultural collaboration (Spires, Paul, Himes, \& Yuan, 2018). Learning community members were also reported to be more responsible and designed their own collaborative norms (Hod \& Ben-Zvi, 2015). Intercultural concepts can be applied through different media for effective teaching and learning in a flipped classroom (Desai, Jabeen, Abdul, \& Rao, 2018 ) whilst classroom management is also influenced by cultural values (Jaber, 2015; Gaias, Johnson, Bottiani, Debnam, \& Bradshaw, 2019).

\section{Cloud Computing for Collaboration}

Collaboration overcomes temporal and spatial obstacles to learning (Huang, 2017). The collaborative working model reportedly achieved better learning outcomes, generated 
collective intelligence, saved time, and enhanced motivation (Mora, Signes-Pont, Fuster-Guillo, \& Pertegal-Felices, 2020). Extant literature showed that the use of computer-supported collaboration influenced learning processes in terms of discussion, justification, and reasoning (Noroozi, Biemans, Busstra, Mulder, \& Chizari, 2011), knowledge sharing and transfer among multidisciplinary groups (Noroozi, Teasley, Biemans, Weinberger, \& Mulder, 2013), and transactive memory system in various disciplinary backgrounds (Noroozi et al, 2013). Emergent technologies such as online fora, cloud applications, and social media can enhance collaboration. Cloud computing applications may influence learning factors on cognitive, emotional, spatial, and group levels, thereby developing students' thinking and problem-solving abilities in the classroom (Schneckenberg, 2014). Cloud-based collaboration in relation to teamwork quality and computer-related self-efficacy significantly and positively influences team performance (Qin, Hsu, \& Stern, 2016). Using cloud services can help students generate positive attitudes (Huang, 2017). Google Slide is a useful computer-supported collaborative learning tool to enhance multi-user learning environment. Google Drive can enhance communication for small groups engaged in case discussions; in particular, it alters power relationships in the classroom and facilitates the development of critical attitudes (Rowe, Bozalek, \& Frantz, 2013). Cloud computing tools (e.g. Google Docs) also provide a solution to data-management problems and enable users to coordinate efforts (Bennett \& Pence, 2011).

\section{Hypotheses Formulation}

In accordance with the objectives, we propose three research questions: (1) Does the jigsaw-based teaching method influence collaboration?, (2)

Does the use of cloud platforms influence collaboration?, and (3) Does the cultural differences among students influence collaboration?. The influence of jigsaw method and cloud platform on collaboration can be explained by the following hypotheses:

H1: The jigsaw-based teaching method positively influences collaboration

Hla: The jigsaw-based teaching method positively influences group learning

H1b: The jigsaw-based teaching method positively influences individual learning in a group

H1c: The jigsaw-based teaching method positively influences social connectedness

H2: The perceived usefulness of cloud platforms positively influences collaboration

H2a: The perceived usefulness of cloud platforms positively influences group learning 
$H 2 b$ : The perceived usefulness of cloud platforms positively influences individual learning in the group

H2c: The perceived usefulness of cloud platforms positively influences social connectedness

In addition, we hypothesise that cultural differences influence collaboration and collaboration influence classroom community and propose the following:

H3: Cultural differences positively influence collaboration

H3a: Cultural differences positively influence group learning

H3b: Cultural differences positively influence individual learning in a group

H3c: Cultural differences positively influence social connectedness

H4: Collaboration positively influences classroom community

H4a: Group learning positively influences classroom community

H4b: Group individual learning positively influences classroom community

H4c: Social connectedness positively influences classroom community

\section{Method}

\section{Research Design}

The proposed jigsaw-based collaborative learning method included three steps: pre-class, in-class, and post-class (Fig. 1). In the pre-class step, teacher prepared weekly the selected case by reading, synthesising, and organising the information for discussion two days prior to the class. In addition, teacher created a Google Slides file for the case and randomly assigned group members (with student IDs on the slide). Lastly, teacher posted the lecture materials and a Google Slides link (available 10 minutes before class) on Google Classroom. Students received a notification via mobiles and could read the materials in advance but were not given their group assignment until class started to avoid absences and students taking advantage of others.

During the in-class step, teacher informed the students who was in their groups at the beginning of the class. After giving a lecture, the teacher asked the groups to find a place for their discussion and distributed relevant instructions to each group. Students first read the content, discussed it, and shared their thoughts ( 30 minutes of discussion), as depicted in Figure 1. Next, each group entered a summary consisting of keywords on Google Slides (15 minutes) and presented group-by-group to assemble the whole of the case (5-minute presentation for each group). Thus, students understood the case by 
piecing together the information. Teacher summarised the full case to conclude the lesson. In the post-class step, students reviewed materials on Google Classroom and the cases on Google Slides by using any device. Students also shared their thoughts after the discussion on Google Classroom.

Figure 1

Experimental procedure

\begin{tabular}{l|ll|}
\hline \multicolumn{1}{c|}{ Pre-class } & \multicolumn{1}{c|}{ In-class } & \multicolumn{1}{c|}{ Post-class } \\
\cline { 3 - 3 } Prepare two days before class & 1.Lecture (120 mins) & 1.Case review (Google slide) \\
1.Case selection & 2.Case discussion (30mins) & 2.Q\&A, Feedbacks \\
2.Google classroom/Google slide & 3.Summary preparation (15mins) & (Google Classroom) \\
3.Group member assignment & 4.Case sharing (5mins/per group) &
\end{tabular}

\section{Collaborative Tools}

Google Classroom and Google Slides were used weekly in this study. Google Classroom provides a web-based platform and a mobile application where teachers can set up assignments and post content on Google Classroom as well as review student work at any time. Google Classroom enables both teachers and students to interact easily on a cloud-based platform and check content or files efficiently. Google Slides were also used to enable collaboration. In this course, students had a case discussion for 60 to 90 minutes (depending on the length of the case). Teacher created a file on Google Slides before the class and randomly assigned group members for the discussion. In class, all students were required to locate their group members and discuss partial content of the case (jigsaw method). After discussing and sharing their thoughts, each group was required to provide summaries of their work on Google Slides and present each one individually. Students were also able to review the slides any time after the class.

Figure 2

Examples of Google Classroom and Google Slides

\section{Participants and measurements}

The participants of this study were full-time students from an 'Information Management' course at National Taipei University of Technology in Taiwan. The course was conducted in the same classroom for three hours per week over 18 weeks in semester 1 of the 2019/2020 academic year. A total of 42 students with an average age of 25 years from 17 countries, including Finland (2), Vietnam (7), Indonesia (5), 
Thailand (10), Italy (2), Germany (2), Turkey (2), France (3), Nicaragua (1), Russia (1), Peru (1), Spain (1), Swaziland (1), India (1), Poland (1), Denmark (1), and Austria (1) participated in the course. The characteristics of participants such as gender, programme of study and year are shown in Table 1.

Table 1

Characteristics of participants

\section{Gender}

Female

Male

Programme \&Year

Undergraduate-3rd year

Undergraduate-4rd year

Graduate-1st

Graduate-2nd

Graduate-others

\section{Programme of study}

$\begin{array}{lr}\text { 40\% Business Administration } & 48 \% \\ \text { 60\% Financial Management } & 19 \% \\ \text { Industrial Engineering } & 7 \% \\ \text { 5\% Business development } & 7 \% \\ 7 \% \text { Computer Science } & 7 \% \\ \text { 45\% Other programmes <2\% each } \\ 31 \% \\ 12 \%\end{array}$

The data collection for this study employed an online questionnaire comprising five sections: personal information, cultural diversity, perceived usefulness of cloud applications, jigsaw satisfaction, and collaboration. To ensure accuracy, ease of understanding, and contextual relevance, a pilot questionnaire was administered an expert panel, who provided input based on their teaching experience. Five items of cultural diversity were adapted from Tapanes, Smith, and White (2009). The measurement for collaboration was adapted from Summers, Gorin, Beretvas, and Svinicki (2005), including 4 constructs with 12 items of social connectedness, 4 items of classroom community (dependent variable), 6 items of group-processing evaluation, and 4 items of group-processing effect on individuals. Four items for perceived usefulness of cloud applications were adapted from Huang (2017). Three items for jigsaw satisfaction were adapted from Leyva-Moral and Camps (2016). For all measures, a seven-point Likert scale was adopted with anchors ranging from 'strongly 
disagree' (1) to 'strongly agree' (7).

\section{Results}

\section{Reliability of scales}

Individual items measuring the constructs were combined to form scales. These measures were then tested for reliability to assess the internal consistency of the instrument. Cronbach's alpha was 0.79 for jigsaw teaching, 0.65 for cultural difference, 0.79 for perceived usefulness, 0.89 for group learning, 0.79 for group individual learning, 0.9 for social connectedness, and 0.86 for classroom community. All values were above 0.6 , which is the minimum acceptable value for Cronbach's alpha (Hair, Black, Babin, Anderson, \& Tatham, 2006).

\section{Regression analysis}

To examine the proposed hypotheses, 12 separate linear regression analyses were conducted. We then examined the coefficients of causal relationships between constructs to validate the hypothesised effects. Table 2 presents the variance and regression weights for each equation in the model. The results revealed that the jigsaw method did not significantly influence group learning or social connectedness but significantly influenced individual learning in a group. Thus, H1a and H1c were not supported but $\mathrm{H} 1 \mathrm{~b}$ was supported $(\beta=0.456)$. Results for hypotheses regarding perceived usefulness of the cloud platform indicated that perceived usefulness significantly influenced group learning but did not influence individual learning in group or social connectedness. Thus, $\mathrm{H} 2 \mathrm{a}$ was supported $(\beta=0.504)$ but $\mathrm{H} 2 \mathrm{~b}$ and $\mathrm{H} 2 \mathrm{c}$ were not supported. Cultural difference significantly influenced collaboration (group learning, individual learning in a group, and social connectedness); hence, $\mathrm{H} 3 \mathrm{a}$ ( $\beta=$ 0.486), $\mathrm{H} 3 \mathrm{~b}(\beta=0.521)$, and $\mathrm{H} 3 \mathrm{c}(\beta=0.693)$ were supported. Collaboration in terms of group learning, individual learning in a group, and social connectedness influenced classroom community. Therefore, $\mathrm{H} 4 \mathrm{a}(\beta=0.526), \mathrm{H} 4 \mathrm{~b}(\beta=0.858)$, and $\mathrm{H} 4 \mathrm{c}(\beta=$ $0.631)$ were supported.

Table 2

Summary of regression analysis results

\begin{tabular}{|l|l|c|c|c|c|}
\hline \multicolumn{1}{|c|}{ Factors } & \multicolumn{1}{|c|}{ Hypothesis } & Adj. R & F-value & $\boldsymbol{\beta}$ & Results \\
\hline $\begin{array}{l}\text { Jigsaw } \\
\text { Method (J) }\end{array}$ & H1a: Jigsaw method->Group learning & -0.003 & 0.878 & 0.132 & Not \\
\end{tabular}




\begin{tabular}{|c|c|c|c|c|c|}
\hline & H1b: Jigsaw method->Group individual learning & 0.252 & $14.833^{* * *}$ & 0.456 & Supported \\
\hline & H1c: Jigsaw method->Social connectedness & -0.024 & 0.049 & 0.036 & $\begin{array}{c}\text { Not } \\
\text { Supported }\end{array}$ \\
\hline \multirow{3}{*}{$\begin{array}{l}\text { Perceived } \\
\text { Usefulness } \\
\text { (PU) }\end{array}$} & H2a: Perceived usefulness->Group learning & 0.086 & $4.865^{* *}$ & 0.504 & Supported \\
\hline & $\begin{array}{l}\text { H2b: Perceived usefulness }->\text { Group individual } \\
\text { learning }\end{array}$ & 0.014 & 1.601 & 0.293 & $\begin{array}{c}\text { Not } \\
\text { Supported }\end{array}$ \\
\hline & H2c: Perceived usefulness ->Social connectedness & 0.059 & 3.554 & 0.507 & $\begin{array}{c}\text { Not } \\
\text { Supported }\end{array}$ \\
\hline \multirow{3}{*}{$\begin{array}{l}\text { Cultural } \\
\text { difference } \\
\text { (CD) }\end{array}$} & H3a: Cultural difference-> Group learning & 0.097 & $5.386^{* *}$ & 0.486 & Supported \\
\hline & $\begin{array}{l}\text { H3b: Cultural difference ->Group individual } \\
\text { learning }\end{array}$ & 0.121 & $6.658^{* *}$ & 0.521 & Supported \\
\hline & H3c: Cultural difference ->Social connectedness & 0.158 & $8.717^{* * *}$ & 0.693 & Supported \\
\hline $\begin{array}{l}\text { Group } \\
\text { learning }(\mathrm{G})\end{array}$ & H4a: Group learning->Classroom community & 0.191 & $10.683^{* * *}$ & 0.526 & Supported \\
\hline $\begin{array}{l}\text { Group } \\
\text { individual } \\
\text { learning } \\
\text { (GI) }\end{array}$ & $\begin{array}{l}\text { H4b: Group individual learning-> Classroom } \\
\text { community }\end{array}$ & 0.524 & $46.085^{* * *}$ & 0.858 & Supported \\
\hline $\begin{array}{l}\text { Social } \\
\text { connectedne } \\
\text { ss (SC) }\end{array}$ & $\begin{array}{l}\text { H4c: Social connectedness-> Classroom } \\
\text { community }\end{array}$ & 0.395 & $27.750^{* * *}$ & 0.631 & Supported \\
\hline
\end{tabular}

In addition, $25.2 \%$ of the variance in individual learning in a group (adjusted $\mathrm{R}^{2}=$ 0.252 ) was explained by the jigsaw method and $8.6 \%$ (adjusted $\mathrm{R}^{2}=0.086$ ) was explained by perceived usefulness of the cloud platform. Cultural differences explained $9.7 \%$ of the variance in group learning (adjusted $\mathrm{R}^{2}=0.097$ ), $12.1 \%$ of the variance in individual learning in group (adjusted $\mathrm{R}^{2}=0.121$ ), and $15.8 \%$ of the variance in social connectedness (adjusted $\mathrm{R}^{2}=0.158$ ). Furthermore, $19.1 \%$ of the variance in the classroom community was explained by group learning (adjusted $\mathrm{R}^{2}=0.191$ ), $52.5 \%$ was explained by individual learning in a group (adjusted $\mathrm{R}^{2}=0.525$ ), and $39.5 \%$ was explained by social connectedness (adjusted $\mathrm{R}^{2}=0.395$ ).

\section{Discussion}

The regression analysis showed that jigsaw-based teaching method had a significant effect on individual learning in the group (Fig. 2). Jigsaw technique is a promising educational technique and efficient method for inter-professional education (Jones and Schwartz, 2018). Our results are consistent with the literature and suggest that the jigsaw teaching method can influence individual learning, while students favour 
the jigsaw method over traditional lecturing to improve problem-solving skills (Wilson, Pegram, Battise, \& Robinson, 2017) and self-regulated learning (Sanaie, Vasli, Sedighi, \& Sadeghi, 2019). Perceived usefulness of the cloud platform (Google Classroom and Google Slides) also influenced group learning during collaboration. Students' feedback emphasised perceived usefulness of Google Classroom cloud platforms as the key to successful collaboration; quotes from the open ended responses illustrate this, 'I really like to use Google Classroom in class because it's really easy to work with' and 'Google Classroom is very user friendly and easy to use'. The findings confirmed by existing literature that cloud-based collaboration significantly influences team performance (Qin, Hsu, \& Stern, 2016), and student learning (Zhou, Simpson, \& Domizi, 2012).

Cultural differences positively influenced group learning, individual learning, and social connectedness in collaboration. Culturally diverse students may influence the outcome of group and individual learning and result in different degrees of social connection with classmates. Qualitative feedback indicated that various cultural factors may influence collaboration, including communication and sharing of opinions (related to social connectedness), culture differences in terms of learning (related to individual learning in a group), and teaching style in discussions (related to group learning). Findings are consistent with Spires, Paul, Himes, \& Yuan, (2018) indicating that group case study fosters students' educational capabilities based on cross-cultural collaboration. Furthermore, group learning, individual learning in a group, and social connectedness influenced the classroom community. By analysing the paths, teachers can use the jigsaw-based case discussion to enhance efficient individual learning and cloud platform to facilitate effective group (collaborative) learning. The emerged cultural differences positively affect atmosphere and collaboration of classroom community and classroom management (Jaber, 2015).

Figure 2

Regression analysis results 


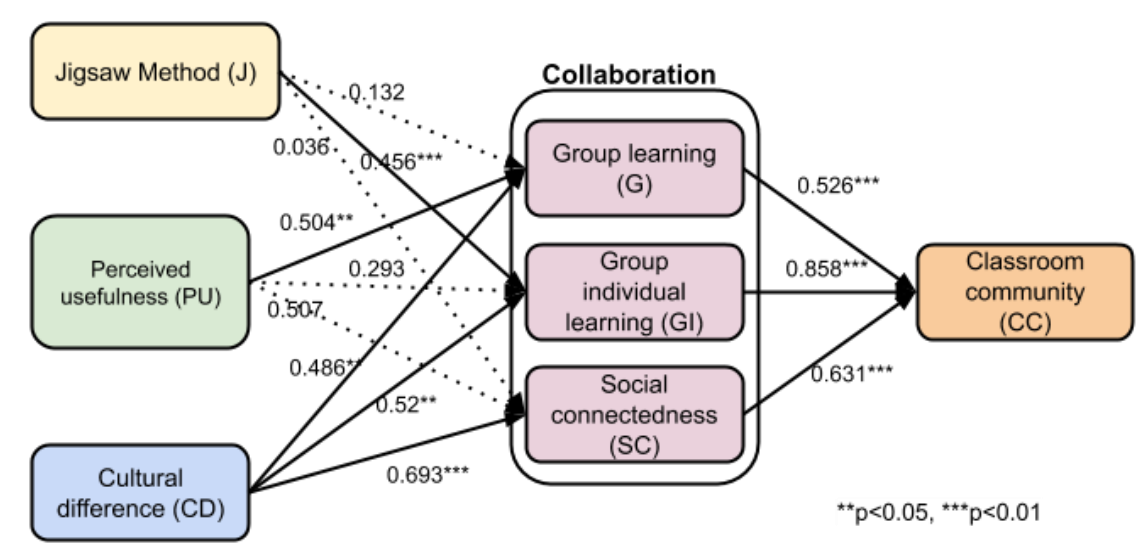

\section{Conclusion}

In this study, we investigated relationships among the jigsaw method, perceived usefulness, cultural differences, collaboration, and the classroom community. The findings revealed jigsaw method influenced individual learning in groups and cloud platforms influenced group learning during collaboration. Jigsaw-based case discussion integrating Google Classroom and Slides can foster efficient and effective cross-group collaboration. Meanwhile, cultural differences impacted collaboration, which also influenced the classroom community. Hence, teachers can make greater use of collaboration to help students learn and enable them to connect with students from different cultures in class. Our contributions include identifying the influence of the jigsaw method with case discussion on individual learning, the effect of using cloud platforms on collaboration, the influence of cultural differences on collaboration, and the positive relationship between collaboration and classroom community.

\section{Limitations}

Our study is not without its limitations. With a limited sample, sample bias for adopting local culture may exist. The findings show that various cultural values and norms in groups influences collaborative learning. The issues of free riders, group pressure, and dominance also limited by the implementation of our method. Group pressure may exist due to dominant student(s) or free rider(s) but volunteers in the group can lead and manage smoothly. Peer learning also minimised the negative influence of free riders. Finally, a control group can be added for comparison and ease the bias of self-reported data. Future studies can include more samples from countries on distinct regions, limit the criteria on sample selection (e.g., first time to study in the 
country), and control the experiments. We welcome further testing of the proposed model on larger student populations.

\section{Disclosure statement}

No potential conflict of interest was reported by the authors.

\section{References}

Al-Samarraie, H., \& Saeed, N. (2018). A systematic review of cloud computing tools for collaborative learning: Opportunities and challenges to the blended-learning environment. Computers \& Education, 124, 77-91.

Alghasab, M., Hardman, J., \& Handley, Z. (2019). Teacher-student interaction on wikis: Fostering collaborative learning and writing. Learning, Culture and Social Interaction, 21, 10-20.

Asterhan, C. S. C., \& Schwarz, B. B. (2016). Argumentation for Learning: WellTrodden. Paths and Unexplored Territories. Educational Psychologist, 51(2), 164187.

Bear, G. G., Chen, D., Mantz, L. S., Yang, C., Huang, X., \& Shiomi, K. (2016). Differences in classroom removals and use of praise and rewards in American, Chinese, and Japanese schools. Teaching and Teacher Education, 53, 41-50.

Bennett, J., \& Pence, H. E. (2011). Managing laboratory data using cloud computing as an organizational tool. Journal of Chemical Education, 88(6), 761-763.

Benson, V. (2008). Unlocking the potential of wireless learning. Learning and Teaching in Higher Education, 2, 42-56.

Benson, V., \& Anderson, D. (2010). Towards a strategic approach to the introduction of blended learning: Challenges faced and lessons learned. British Journal of Educational Technolog, 41

Buhr, G. T., Heflin, M. T., White, H. K., \& Pinheiro, S. O. (2014). Using the jigsaw cooperative learning method to teach medical students about long-term and postacute care. Journal of the American Medical Directors Association, 15(6), 429-434.

Chan, S. C., Wan, J. C., \& Ko, S. (2019). Interactivity, active collaborative learning, and learning performance: The moderating role of perceived fun by using personal response systems. International Journal of Management Education, 17(1), 94-102. 
Charlier, N., Van Der Stock, L., \& Iserbyt, P. (2016). Peer-assisted learning in cardiopulmonary resuscitation: the jigsaw model. Journal of emergency medicine, 50(1), 67-73.

Chen, C.M. \& Kuo, C.H. (2019). An optimized group formation scheme to promote collaborative problem-based learning. Computers \& Education, 133(1), 94-115.

Denessen, E., Driessen, G., Smit, F., \& Sleegers, P. (2001). Culture differences in education: Implications for parental involvement and educational policies. A bridge to the future, 55-66.

Desai, S. V., Jabeen, S. S., Abdul, W. K., \& Rao, S. A. (2018). Teaching cross-cultural management: A flipped classroom approach using films. The International Journal of Management Education, 16(3), 405-431.

Gaias, L. M., Johnson, S. L., Bottiani, J. H., Debnam, K. J., \& Bradshaw, C. P. (2019). Examining teachers' classroom management profiles: Incorporating a focus on culturally responsive practice. Journal of School Psychology, 76, 124-139.

Gillies, R. M., \& Boyle, M. (2008). Teachers' discourse during cooperative learning and their perceptions of this pedagogical practice. Teaching and Teacher Education, 24, 1333-1348.

Gillies, R. (2003). The behaviors, interactions, and perceptions of junior high school students during small-group learning. Journal of Educational Psychology, 95(1), 137-147.

Gürbüz, R., \& Birgin, O. (2012). The effect of computer-assisted teaching on remedying misconceptions: The case of the subject "probability". Computers \& Education, 58(3), 931-941.

Hair, J. F., Black, W. C., Babin, B. J., Anderson, R. E., \& Tatham, R. L. (2006). Multivariatedata analysis (6th ed.). Upper Saddle River, NJ: Prentice-Hall.

Han, I., Eom, M., \& Shin, W. S. (2013). Multimedia case-based learning to enhance pre-service teachers' knowledge integration for teaching with technologies. Teaching and Teacher Education, 34, 122-129.

Hod, Y., \& Ben-Zvi, D. (2015). Students negotiating and designing their collaborative learning norms: A group developmental perspective in learning communities. Interactive Learning Environments, 23(5), 578-594.

Hofstede, G. (1986). Cultural differences in teaching and learning. International Journal of intercultural relations, 10(3), 301-320. 
Huang, Y.-M. (2017). Exploring the intention to use cloud services in collaboration contexts among Taiwan's private vocational students. Information Development, 33(1), 29-42.

Jaber, N. Z. (2015). An Analysis of the Palestinian Culture Using Hofstede's Cultural Framework and its' Implication on Teachers' Classroom Practices and Student's Cultural Identity. Procedia-Social and Behavioral Sciences, 205, 292-295.

Jones, K. F., \& Schwartz, A. W. (2018). Jigsaw Education Technique to Teach Geriatrics Palliative Care Principles to an Interprofessional Team. Journal of Pain and Symptom Management, 56(6), e86.

van Leeuwen, A., \& Janssen, J. (2019). A systematic review of teacher guidance during collaborative learning in primary and secondary education. Educational Research Review, 27, 71-89.

Leyva-Moral, J. M., \& Camps, M. R. (2016). Teaching research methods in nursing using Aronson's Jigsaw Technique. A cross-sectional survey of student satisfaction. Nurse education today, 40, 78-83.

Mora, H., Signes-Pont, M. T., Fuster-Guilló, A., \& Pertegal-Felices, M. L. (2020). A collaborative working model for enhancing the learning process of science \& engineering students. Computers in Human Behavior, 103, 140-150.

Moskowitz, J. M., Malvin, J. H., Schaeffer, G. A., \& Schaps, E. (1985). Evaluation of jigsaw, a cooperative learning technique. Contemporary educational psychology, 10(2), 104-112.

Noroozi, O., Biemans, H. J., Busstra, M. C., Mulder, M., \& Chizari, M. (2011). Differences in learning processes between successful and less successful students in computer-supported collaborative learning in the field of human nutrition and health. Computers in Human Behavior, 27(1), 309-318.

Noroozi, O., Weinberger, A., Biemans, H. J., Mulder, M., \& Chizari, M. (2013). Facilitating argumentative knowledge construction through a transactive discussion script in CSCL. Computers \& Education, 61, 59-76.

Noroozi, O., Teasley, S. D., Biemans, H. J., Weinberger, A., \& Mulder, M. (2013). Facilitating learning in multidisciplinary groups with transactive CSCL scripts. International Journal of Computer-Supported Collaborative Learning, 8(2), 189-223. 
Noroozi, O., Biemans, H. J., Weinberger, A., Mulder, M., \& Chizari, M. (2013). Scripting for construction of a transactive memory system in multidisciplinary CSCL environments. Learning \& Instruction, 25, 1-12.

Pozzi, F. (2010). Using Jigsaw and Case Study for supporting online collaborative learning. Computers \& Education, 55(1), 67-75.

Popov, V., Noroozi, O., Barrett, J. B., Biemans, H. J., Teasley, S. D., Slof, B., \& Mulder, M. (2014). Perceptions and experiences of, and outcomes for, university students in culturally diversified dyads in a computer-supported collaborative learning environment. Computers in Human Behavior, 32, 186-200.

Qin, L., Hsu, J., \& Stern, M. (2016). Evaluating the usage of cloud-based collaboration services through teamwork. Journal of Education for Business, 91(4), 227-235.

Sanaie, N., Vasli, P., Sedighi, L., \& Sadeghi, B. (2019). Comparing the effect of lecture and Jigsaw teaching strategies on the nursing students' self-regulated learning and academic motivation: A quasi-experimental study. Nurse education today, 79, 35-40.

Schneckenberg, D. (2014). Easy, collaborative and engaging-the use of cloud computing in the design of management classrooms. Educational Research, 56(4), 412-435.

Slavin, R. E. (2014). Cooperative learning and academic achievement: Why does groupwork work? Anales de Psicología/Annals of Psychology, 30(3), 785-791.

Spires, H. A., Paul, C. M., Himes, M., \& Yuan, C. (2018). Cross-cultural collaborative inquiry: A collective case study with students from China and the US. International Journal of Educational Research, 91, 28-40.

Stahl, G. (2013). Theories of cognition in collaborative learning. In The international handbook of collaborative learning (pp. 86-102). Routledge.

Strijbos, J. W., Martens, R. L., \& Jochems, W. M. (2004). Designing for interaction: Six steps to designing computer-supported group-based learning. Computers \& Education, 42(4), 403-424.

Summers, J. J., Gorin, J. S., Beretvas, S. N., \& Svinicki, M. D. (2005). Evaluating collaborative learning and community. The Journal of Experimental Education, 73(3), 165-188.

Tapanes, M. A., Smith, G. G., \& White, J. A. (2009). Cultural diversity in online learning: A study of the perceived effects of dissonance in levels of 
individualism/collectivism and tolerance of ambiguity. The Internet and Higher Education, 12(1), 26-34.

Weinberger, A., \& Fischer, F. (2006). A framework to analyze argumentative knowledge construction in computer-supported collaborative learning. Computers \& education, 46(1), 71-95.

Weinberger, A., Stegmann, K., \& Fischer, F. (2007). Knowledge convergence in collaborative learning: Concepts and assessment. Learning and instruction, 17(4), 416-426.

Wilson, J. A., Pegram, A. H., Battise, D. M., \& Robinson, A. M. (2017). Traditional lecture versus Jigsaw learning method for Teaching Medication Therapy Management (MTM) core elements. Currents in Pharmacy Teaching and Learning, 9(6), 1151-1159.

Zambrano, J., Kirschner, F., Sweller, J., \& Kirschner, P. A. (2019). Effects of prior knowledge on collaborative and individual learning. Learning and Instruction, 63, 101214.

Zhou, W., Simpson, E., \& Domizi, D. P. (2012). Google docs in an out-of-class collaborative writing activity. International Journal of Teaching and Learning in Higher Education, 24(3), 359-375.

Zhou, W., \& Li, G. (2015). Chinese language teachers' expectations and perceptions of American students' behavior: Exploring the nexus of cultural differences and classroom management. System, 49, 17-27. 